was that of a young child; and in this case a seton was inserted, but it did not produce any reaction. With my increased experience, I think that both these cases might have been successfully treated by irritating setons or caustic darts.

No case of vascular bronchocele having presented itself in the 211 cases on which the present paper is based, this variety will not be bere considered.

I have reserved till the end consideration of the advisability of surgical interference in cases of goitre. Some eminent surgeons are of opinion that no treatment should be adopted unless there be danger to life, or at least serious disturbance of function; and even in such cases only recommend palliative measures, such as the simple puncture of cysts, or the attempt, often unsuccessful, of tracheotomy. Billroth says that operations should not be performed for "cosmetic" effect; but seeing that so many operations are daily performed with a view of removing defects of personal appearance far less objectionable than that of bronchocele, Billroth's dogma can scarcely meet with general acceptance, especially when it is further remembered that at any time the disease may become dangerous to life.

The rule which I have adopted is, not to recommend patients to undergo treatment unless there is serious embarrassment of function, or continuous increase of the tumour; but as none of the various methods of treatment employed by me have hitherto been attended with fatal results in my practice, I have always been willing to carry out treatment when the patient has desired it on account of disfigurement.

If I have not referred to various other measures, such as ligature of the thyroid arteries, division of the sterno-cleidomastoid muscle, and removal of the entire thyroid gland,* it is because I have not yet met with a case in which I have deemed such measures necessary.

Weymouth-street, W., April, 1872.

\section{ON INCONTINENCE OF URINE IN CHILDREN.}

BY J. WARRINGTON HAWARD, F.R.C.S.,

ISSTSTANT-SURGEON TO THE HOSPITAL FOR STOK OHILDREN

AMONG the minor ailments of children, one of the most sommon and troublesome is incontinence of urine-an affection which, besides the misery and ridicule that it often brings upon those subject to it, not infrequently, in an indirect manner, gravely interferes with their health. True incontinence of urine in adults usually indicates serious disease of the nervous centres, and has quite a different meaning and importance to that met with, as a rule, in shildhood; wherefore I shall confine these remarks to the affection as it occurs in children and young persons. Although it is in these of much less serious import than the same symptom occurring in adult life, and depends, generally, upon much more remediable and transient causes, yet even here its effects are of ten very distressing. There are several cases on record, and I have myself seen two, in which the urethra has been cut through by a string tied tightly round the penis by boys anxious thus to prevent the escape of urine during sleep. A troublesome eczema, and even considerable ulcers, may be produced by the constant irritation of the urine upon the skin: a condition which, when combined with any disease requiring confinement to bed, often leads to serious bed-sores. For this reason, it is always desirable, when any surgical operation is to be undertaken on a patient with this affection, to first cure, if possible, the incontinence. I have lately had a good example of this in a boy who came under my care for the treatment of talipes, which had failed owing to the occurrence of sloughs wherever any pressure was made on the foot, and the boy had besides two large and deep ulcers over both hips. I found that he was constantly wet from the involuntary escape of urine-a condition that I have observed is often associated with talipes, kut which in his case was

* This operation has lately been performed with great brilliancy and suceess by Professor Greene, of New York, and those who are interested in the subject are referred to bis very complete article in the "American Journal of Medical Science" for January, 1871 . due to congenital phimosis. I at once circumcised him, and thereby cured the incontinence, and at the same time the tendency to sloughing; the sores on the hips began at once to heal, and the talipes was easily remedied. Besides these physical evils, incontinence of urine of ten brings upon the unhappy child a painful amount of persecution, depriving it of many of its natural pleasures, and perhaps materially interfering with its education.

The treatment of this affection, then, is not without interest, and its success will depend very much upon the accurate recognition of its causes; for these are manifold and various. And first, the cases may be broadly divided in to two chief classes: $(a)$ those depending upon deficient nerrous or muscular action; $(b)$ those which have for their cause an excess of this action. The normal retention and passing of urine depend upon the proper balancing of the expulsive and retentive forces-that is to say, of the muscular walls and of the sphincter of the bladder. And this balance may be disturbed either by a want of sphincter power or an excessive expulsive power. Now the first of these-the want of sphincter power-is, I believe, in children, much the less frequent of the two causes, and is usually associated with delicate health, spinal curvature, talipes, or other paraly tic affections ; it is also the more troublesome to cure. The second and more common cause, the excess of expulsive power, occurs, on the other hand, in perfectly healthy children, and may depend upon the condition of the urine, or of the bladder, or upon some neighbouring or eccentric irritation, and is of the two much the more easily remedied. There is no doubt also a certain, but I believe a small, number of cases which depend upon mere indolence and bad habit; and these must be treated by careful management, and, if need be, punishment; which, I may remark, should not depend upon the temper or caprice of a nurse, but should be carried out in an intelligent manner.

In the cases due to want of sphincter power there is usually incontinence by day as well as by night; the water escapes very frequently and in small quantities, and the child is constantly wet; they are mostly associated with general nervous and muscular debility, and the expulsive power of the bladder is also weakened. These cases will be benefited by tonics, and especially by strychnia. I have seen excellent results from this remedy, but it must be persevered with and given in sufficient doses, and not relinquished if it does not in the first week or two produce much benefit; for it must be remembered that this class of cases always requires prolonged treatment. I have also seen benefit from the liquid extract of ergot, but this is less to be depended upon than strychnia; and several children in which all other means had failed, I have cured at once by the application of solid nitrate of silver to the neck of the bladder, or the orifice of the urethra. These were all girls. The majority of cases, however, depend upon the second cause-an excess of nerrous or muscular action. And in these the balance of expulsive and sphincter power is not, I believe, altered by the weakening of the sphincter, but by a spasmodic expulsive action which the sphincter is incapable of resisting. Thus, during the day, by voluntarily adding to the contraction of the sphincter, the effects of this expulsive spasm may be to some extent resisted, and the water is retained; moreover, as in some other spasmodic affections, these involuntary contractions occur less frequently in the day than during sleep, when the voluntary controlling powers are in abeyance. A grain, the causes of this kind of incontinence are of an irritant nature, and such as to excite spasm rather than to weaken the sphincter; a view which is besides corroborated by the fact that the most effectual remedies are those which remove irritation and allay nervous and muscular excitement. It is remarkable, too, that, like chorea and epilepsy, the incontinence often ceases during an acute illness, but returns with convalescence. In boys, I think, by far the most common cause of this muscular spasm is the existence of congenital phimosis, which, from its retaining the secretion round the glans, the barrier - which it offers to proper cleanliness, and the adhesions which it frequently leads to between the preputial mucous membrane and the glans, is a constant source of irritation. I have seen so many children mercilessly dosed with iron and cther physic, when the incontinence was at once cured by circumcision, that I cannot avoid laying some stress upon the apparently obvious necessity of examining the urinary organs of all 
children suffering from incontinence. And I would point out that in many of these boys a very moderate degree of phimosis will be sufficient to cause incontinence; there is often an excessive length of prepuce with but little contraction of the orifice; such cases are almost certainly cured by circumcision. It must be remembered, however, that a bad habit of ten persists after its original cause is removed, and therefore it is sometimes necessary to take some pains to break these children of the habit of passing water during the night for the first week or two after the operation; as, for instance, by waking them a little later every night; measures which, though ineffectual before the operation, will after it soon be successful. Many of these cases, however, are at once cured by the operation without any further trouble. Another frequent source of irritation is the presence of ascarides in the rectum, and thus the incontinence may sometimes be cured by a compound scammony powder, followed by iron. Fissure of the anus, though not common in children, may also cause incontinence of urine, and it is remarkable sometimes how much of the inconvenience is referred to the bladder rather than to the real seat of disease. Of course this would be treated by the appropriate operation. Excessive acidity of the urine is another cause which, it will be remembered, depends usually upon disordered digestion, and must be treated accordingly. Alkaline urine is occasionally present in these cases, and, when not associated with cystitis, is generally found in hysterical girls. In these, phosphoric acid, chalybeates, and valerian will be the most appropriate remedies.

Incontinence of urine is sometimes the only symptom of stone in the bladder, especially if the stone be a very large one, so that sounding must not be omitted in our investigation into the causes of this affection. But there remain certain cases, and of these not a few, in which we can discover no cause whatever for the affection; and these are they which are, as a rule, to be cured by belladonna. To prevent disappointment it is needful to take care that the preparation of the drug is a good one, for specimens of belladonna differ much in potency. The extract is, I think, the best form of giving it, and should be administered in doses commencing at one-sixth or a quarter of a grain, and, if necessary, increased till some dryness of the fauces or other physiological effects are produced; if then there is no improvement it is not likely to be beneficial. It matter's little whether it is given during the day or only at night. Chloral has been highly spoken of as a remedy for this affection; but, though I have tried it pretty extensively, I have not found it nearly so efficient as belladonna. Neither have I found blisters, which are recommended to be applied to the sacrum or umbilicus, of much use. Bromide of potassium and cantharides are also by some recommended, but have generally failed in my hands. I have recently been testing the efficacy of all these remedies, and my opinion of them is founded upon that experience. Nevertheless, they will some of them doubtless succeed when others fail; but of the cases for which no cause can be found, there are, I think, very few indeed which are not to be cured by belladonna.

Queen Anne-street, W., May, 1872.

ON THE

DANGER OF FORCIBLE DISTENSION OF THE RECTUM IN CASES OF OBSTRUCTION OF THE BOWELS.

Bч T. P. HESLOP, M.D.,

PHYSICIAN TO THE QUBEN'S AND CHILDREN'S HOSPITALS, BIRMINGHAM.

A CASE was recorded in the columns of THE LANCET of April 13th which illustrates a danger, as regards a certain procedure, not so fully recognised as it deserves to be. A married woman, aged thirty-three, suffered from obstruction of the bowels. No relief taking place for several days, Amussat's operation was considered, but the supervention of a syncopal condition caused it to be abandoned. The medical attendant now determined upon introducing his hand into the rectum, and a stricture was discovered in the sigmoid flexure of the colon. Some water was injected through the opening, with the result of bringing down a very large quantity of fæcal matter and fluid. Three hours after this operation the patient died. The necropsy is thus described :- " On opening the abdomen about a pint of fluid was found in the peritoneal cavity, most of which had probably escaped from the bowel, which had been perforated by an ulcer at the seat of stricture at the lower part of the sigmoid flexure. The small intestines were much distended, the large ones empty, and both were much congested." It can scarcely be doubted that the ulcer was torn by the wellintentioned efforts of the operator, and that the result of this tear was the outpouring of fluid into the abdominal cavity. Nothing is said of peritonitis, which must have been produced bad the perforation preceded death by many hours. When the state of bowel at the seat of stricture is considered, its loss of elasticity, its constriction, its frequently changed relations to neighbouring parts, it would be wonderful if an ordinary hand could be introduced, however gently, into the rectum without endangering a rupture of the diseased part.

I have felt compelled to draw this conclusion because the case forcibly reminds me of such an accident which occurred in my practice many years ago under similar circumstances. I was summoned by a Birmingham surgeon to see a young woman suffering from intestinal obstruction. No relief having been obtained from the means employed, my col. league declared his desire to pass his hand into the bowel to which I assented. The case ended fatally, and at the necropsy we observed a similar condition of the colon to that above described, inclusive of the lacerated state. The danger of bringing about such a catastrophe as this last is obvious. The corollary I drew was that, however indispensable in such cases may be the digital examination of the bowel and pelvic cavity, the introduction of the hand into the rectum should be a procedure undertaken only exceptionally, and after grave consideration; and, moreover, that the possible results of the procedure should be ex. plained to those interested.

Birmingham, April, 1872.

\section{H Y D A T I D S I N TH E K I D N E Y.}

BY A. B. SHEPHERD, M.A., M.B.

ASSTSTANT-PHYSICTAN TO THE HOSPITAL, VICTORIA PARK, ETC.

For the notes of the following case $I$ am indebted to $m$ friend, Mr. H. G. Budd, of Worcester, with whom I saw the patient.

W. R-, aged fifty-one, a coachman, a strong healthy man, has, for the last three years, at varying intervals of time, passed per urethram large quantities of hydatid cysts. Beyond a dull pain in the back and left side, and a more frequent desire to micturate, he has not suffered any inconvenience, except once, eighteen months ago, when he was confined to his bed for a week; he was feverish and complained of pain in the left flank. In the left kidney region was a large tumour, tense, elastic, and dull on percussion. This tumour disappeared entirely in the course of a few days, after the passage of a large number of hydatids. Since that time he has passed a few at intervals, but has not been again laid up.

Rayer ("Traité des Maladies des Reins," Paris, 1841, t. iii., p. 545) observes of hydatids of the kidneys, "Cette altération des reins, très rare chez l'homme, est assez com. mune chez d'autres animaux, surtout chez le mouton." Davaine ("Traité des Entozoaires," Paris, 1860, p. 524) makes the same remark as to their rarity, and gives briefly thirty-nine cases observed by different writers, including Rayer's cases, and two recorded by Barker ("On Cystic Entozoa in the Human Kidney," London, 1856). Leuckart ("Die Menschlichen Parasiten," i. 378) contents himself with the mention of Davaine's cases. Eight may be found recorded in the Med. Times and Gaz., 1855, i. 159, 235, and another in The Lancet, 1855, ii. 366. Some of these are incorporated with others, to the number of thirty-eight, in a thesis by Béraud ("Des Hydatides des Reins," Paris, 1861). The Pathological Society's Transactions (iv. 194; xv. 247) contain two cases in which the cysts were found after death. The second presents an odd coincidence, inas- 